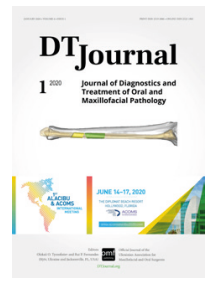

Section-Images in Oral \& Maxillofacial Surgery

Camilo Mosquera, DDS, Editor

\title{
Parotid Gland Lipoma in a 52-Year-Old Patient
}

Olena 0. Ivanchenko \& Valentyn H. Demidov
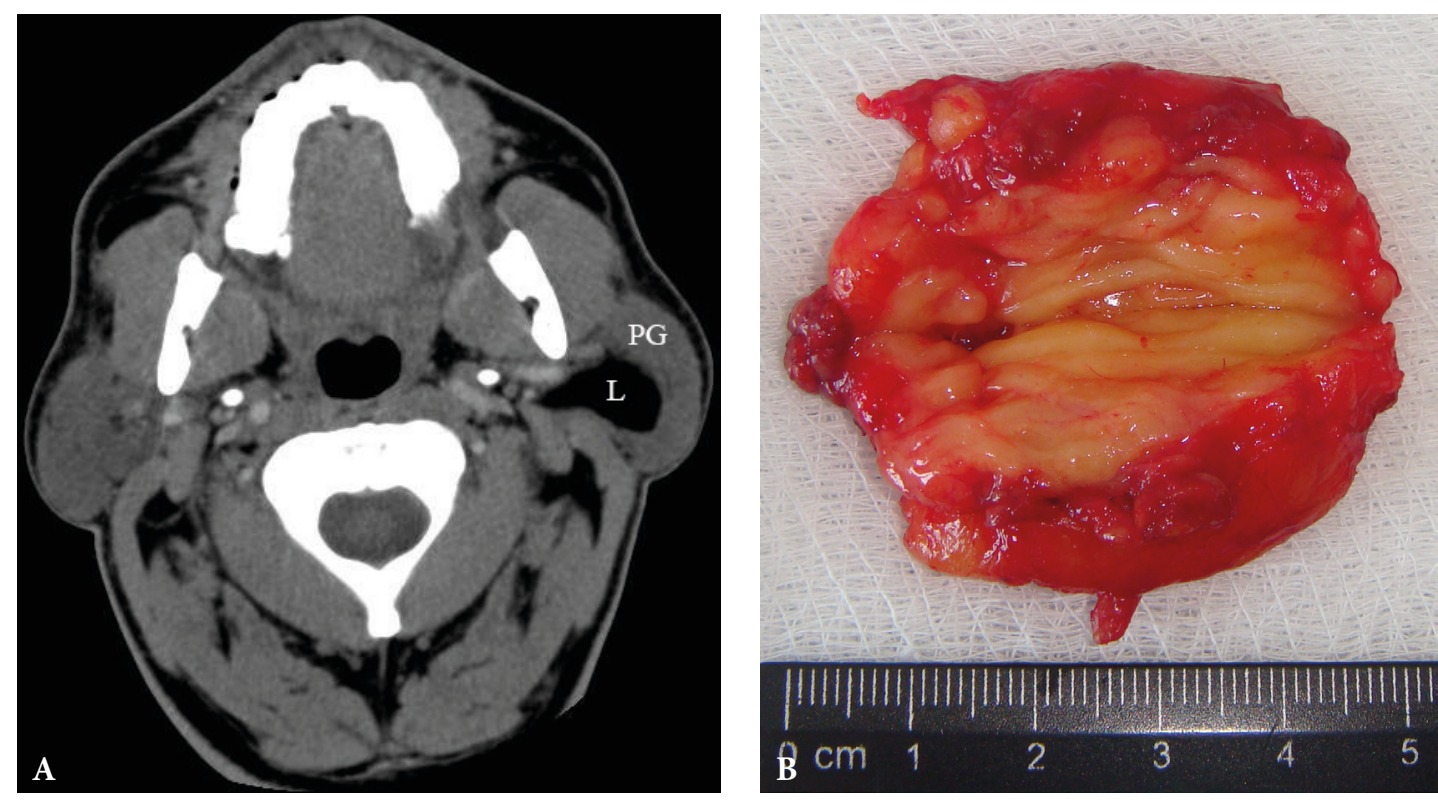

\begin{abstract}
A 52-year-old Caucasian man was referred to hospital with complaints for a painless, slow-growing swelling in the area of left parotid gland during last several years. Disruption of the function of the facial muscles was not observed. Palpation revealed a soft, painless lesion in deep layers of parotid and without symptom of "pseudofluctuation." Contrast-enhanced computed tomography (Panel A) showed well marginated, lower attenuation lipoma $(L)$ with -120 Hounsfield Unit values and no contrast enhancement. Tumor was located deeper to the superficial lobe of
\end{abstract}

Kyiv Regional Clinical Hospital, Kyiv, Ukraine

a Radiologist, Regional Diagnostic Center E-mail: alena_0807@ukr.net

b Oral Surgeon, Center of Maxillofacial Surgery and Dentistry E-mail: valentyn.demidov@ukr.net the left parotid gland $(P G)$ and was totally enucleated under general anesthesia using a cervicomastoidfascial incision (synonyms: Blair incision and classic parotidectomy incision). A well encapsulated lipoma (Panel B) measured $4.7 \mathrm{~cm}$ in a longitudinal direction. Histopathology confirmed the diagnosis due to the presence of simple fat tissue with capsule and helped to distinguish from unusual variants (myxoid lipoma, spindle cell lipoma, liposarcoma). Postoperative period was smooth with no signs of the facial nerve dysfunction. $=$ DTJournal

How to cite this article: Ivanchenko OO, Demidov VH. Parotid gland lipoma in a 52-year-old patient. J Diagn Treat Oral Maxillofac Pathol 2020;4(1):22.

https://dx.doi.org/10.23999/j.dtomp.2020.1.4.

(C) 2020 OMF Publishing, LLC. This is an open access article under the CC BY license (http://creativecommons.org/licenses/by-nc/4.0/). 